$\begin{gathered}\text { EPiC Series in Education Science } \\ \text { Volume 1, 2017, Pages 297-304 }\end{gathered}$
$\begin{gathered}\text { AUBEA 2017: Australasian Universities Build- } \\ \text { ing Education Association Conference 2017 }\end{gathered}$

\title{
Global Mobility Experience of Outbound Construction Management Students: The Case of Western Sydney University
}

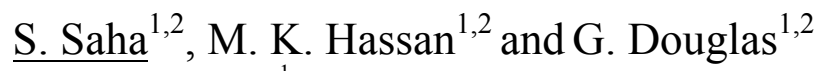 \\ ${ }^{1}$ Academic, SCEM \\ ${ }^{2}$ Western Sydney University, Parramatta, Australia \\ s.saha@westernsydney.edu.au, m.hassan@westernsydney.edu.au, g.douglas@westernsydney.edu.au
}

\begin{abstract}
This study focuses on enhancement of job opportunities in international and national markets for construction management students by providing global construction industry experience (IE) placement. There is an increasing trend towards globalisation in the construction industry. This sort of construction training in the international context also improves student's learning experience and global connections. The Australian Government's New Colombo Plan scholarship provides funding for work and study experience for Australian students travelling to the Indo-Pacific region to further their education. All Australian universities welcome significant numbers of inbound international students as well as increasingly encouraging outbound student mobility. This paper reports on the experiences of a number of outbound students who are involved in studying construction management. Through case study research, it was found that international work placements broadened the knowledge of students highlighting similarities and differences when working in an overseas country. Students made useful contacts and were able to improve their employability in both the local and international construction management sector. Their industrial placement was facilitated by the Australian Institute of Building and Hong Kong Institute of Project Managers through professional networks. This study also recommends that this sort of industrial placement and student exchange programs can enhance their communication skills and understanding of the global construction industry practices.
\end{abstract}

\section{Introduction}

Many students obtain an exciting opportunity to undertake part of their studies overseas and to develop skills in communication, analytical ability, and problem solving while enhancing motivation, independence and confidence (Hardie and Saha 2016). Global mobility of outbound students may

M. Lamb (ed.), AUBEA 2017 (EPiC Series in Education Science, vol. 1), pp. 297-304 
involve internships, semester exchanges, study tours and work placement shadowing (AIM Overseas, 2017). Global mobility team provides advisory, compliance and administrative services, along with outstanding technology, to make this seamless for overseas study. Global mobility makes the movement of employees as streamlined and cost effective as possible, both domestically and globally.

Over the past decade, there is an increasing trend towards globalisation in the construction industry (Hardie and Saha 2016). Industry experience (IE) placement has performed a valuable role in enhancing discipline-related skill sets, improving confidence and making student more employable (Pirie and McNicholoas, 2015). Industrial training imposes a significant influence on student's professional development and employability (Mendez, 2008). Researchers and scholars investigated this field of study in various aspects such as the effectiveness of internship (Beard, 2007), its relationship with employability (Knouse et al., 1999), the framework of the internship program (Narayanan et al., 2010) and its impact on the performance of the students (Hardie and Saha, 2016). However, there is limited study on global mobility for Australian students in the construction management fields abroad. Research both in Australia and internationally shows that the benefits of international mobility are far reaching and they reward the individual, future employers, and industry as well as sending and receiving training providers (AIM Overseas, 2017). Global mobility is still a relatively new phenomenon in vocational/professional education and training in Australia (Hardie and Saha 2016). Despite the global movement of students growing significantly over the past decade, Australian students engaged in vocational education and training have not been afforded many international exchange and placement opportunities (AIM Overseas, 2017). However, the mobility of employees has increased by $25 \%$ over the past decade with further growth up to $50 \%$ expected by 2020 (Price Waterhouse Coopers, 2017). The benefits of outbound mobility for Australian training providers (AIM Overseas, 2017) can be summarised as:

1) enhanced bilateral and multilateral networks and partnerships,

2) enhanced institutional positioning and increased demand for programs,

3) increased organisational awareness of international activities and opportunities,

4) access to professional development for educational staff,

5) globally aware graduates trained with up to date international trends and practices, and

6) a well-rounded professional and sustainable internationalised education program.

In order to achieve these benefits, the Australian government established the "New Colombo Plan" in 2014 creating a source of funding to provide opportunities for Australian undergraduates to study and undertake work placements in the Indo-Pacific region. This program offers funding for scholarships for overseas study, mobility grants for short-term study, internships, mentorships, practicums and research initiatives. This sort of training in the international context will lift Australia's profile in the region and can become a driving force for future prosperity (Hardie and Saha, 2016). The Australian Government has committed more than AU $\$ 150$ million between 20152016 and 2018-2019 periods for this scheme (New Colombo Plan, 2016). The schemes funding allocations for each year is reported in Figure 1. 


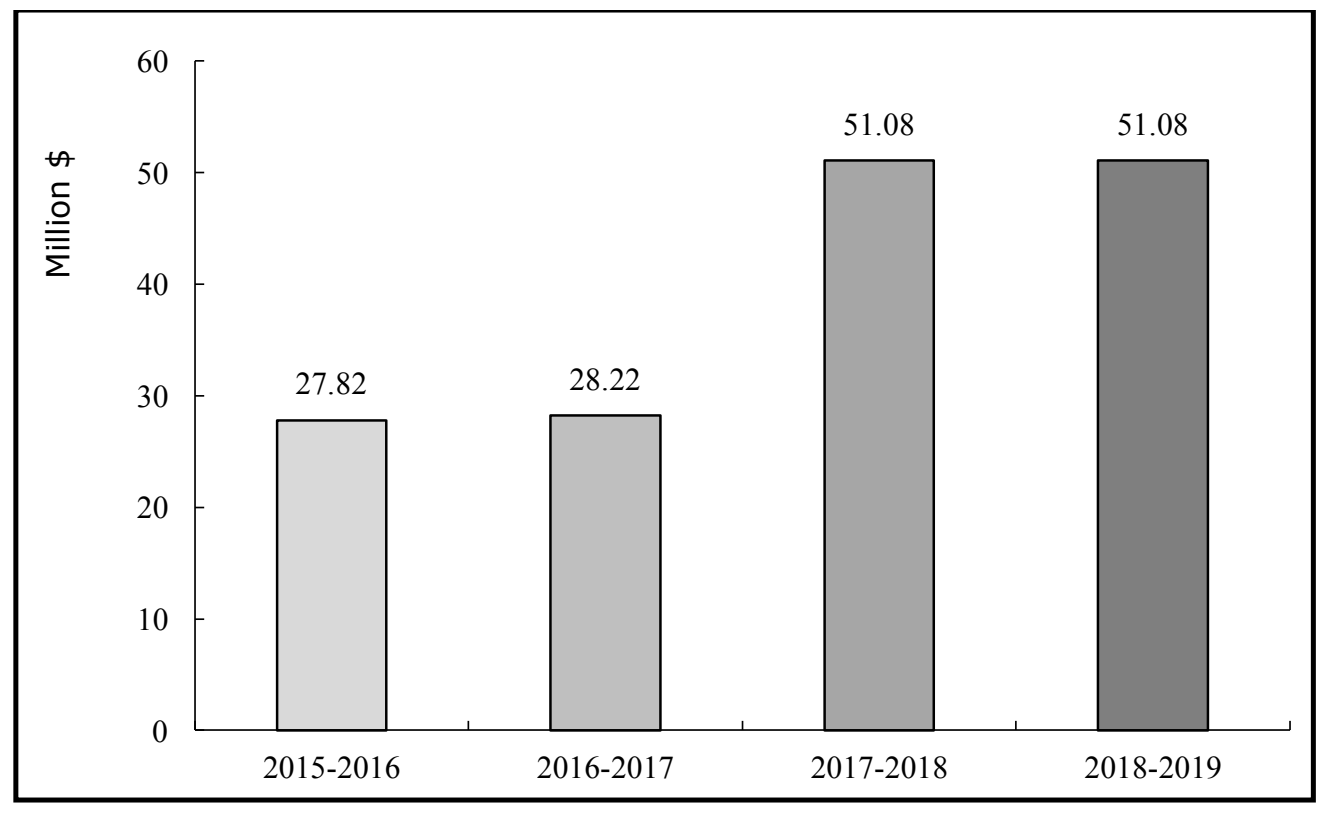

Figure 1: Mobility program funding for New Colombo Plan 2015-2016 to 2018-2019

The purpose of this study is to explore the benefits of the Colombo Plan scholarship for Western Sydney University students located in Hong Kong for industry experience in construction management. The main objectives of this study are to:

1) assess the improved employability of students in the local and international construction sector,

2) reveal enhanced networking and communication skill developments, and

3) highlight the new knowledge gained by students in a professional environment.

\section{Research Methodology}

The research method chosen for this paper is a single case study design, which is made up of individual observations and data collected in interviews. Case study methodology as described by Yin (2014) is a suitable research methodology to address the "how" and "why" research questions especially when the study focus is contemporary rather than historical (Hardie and Saha 2016). The case study on construction work experience in Hong Kong in 2015-2016 was conducted within the discipline of Construction Management (CM) at Western Sydney University (WSU). The case study data consists of reports submitted by the students immediately followed by an interview after their return from the placement and employer comments submitted at the end of the placement. This process involved unstructured interviews focusing on the impact of the work placement on their careers as well as student self-reflection. This case study research was subjected to Western Sydney University ethics approval. Host industrial partners were also surveyed online so as to receive feedback on students' performance and explore the viability of future support of this mobility program. 


\section{Background of the WSU Global Mobility Program}

Western Sydney University (WSU) has a strategic mission that offers an innovative and accessible range of student mobility programs with international partners to support their development as global citizens. The CM discipline at WSU has a teaching philosophy of blending industrial experience with academic learning, encouraging students to engage with global mobility programs through internships. The University strongly supports the CM group in enhancing outbound student mobility through international industry placement for improved employability of students in the local and international construction sector. This mobility program also aims to improve retention rate of high quality students in the CM programs at the Western Sydney University. Academic staff and WSU Careers Advisors were involved in recruiting students undertaking CM courses at WSU to participate in a five-week internship in Hong Kong, during 2015-2016 summer break.

Prior to 2015, there had not been any systematic targeting of students within the construction management degree at Western Sydney University for outbound placements. Any overseas placements relied upon the motivation of individual students and staff on an ad hoc basis. Under the Global Canopy project led by RMIT University a more intensive targeted approach to global mobility (McLaughlin et al., 2017) was adopted. Western Sydney University team members comprising a student and a staff member visited Hong Kong in 2015 and subsequently attended a meeting with prospective candidates at the Global Showcase event held at RMIT University, Melbourne, in April 2016. WSU participants shared their relevant experiences gained during their visit in Hong Kong with both inbound and outbound students at the RMIT showcase.

Recognising that opportunities in construction management within Asia was a key element of the project, staff promoted the concept of on the job training and work experience internships as a component of the mobility project. This was attractive to students as the project provided five weeks of industry experience which was recognised as part of the mandatory industry based learning subject of their degree.

\subsection{Selection Process}

In 2015, all CM students from within the undergraduate degree program were invited to submit expression of interest for the international mobility program as part of the Colombo Plan scholarship. Ten scholarship awards were available. The program consisted of internships aimed at leading construction companies in Hong Kong. Construction management students were required to observe how technology, logistics, contractual obligations and economics interact on large scale building projects. To ameliorate some of the challenges with mobility successful candidates were interned in pairs within one of the participating organisations. Applicants seeking the Colombo Plan scholarship were required to write at least one to two paragraphs outlining the achievement in the following aspects:

1) work experiences with actual examples;

2) academic performance; and

3) community activities.

Students were also required to satisfy the following specific criteria of the internship program:

- Completion of a 'General construction induction' program (white card).

- Strong interest in project management and the effective delivery of building projects.

- General understanding of office procedures and quality control methods.

- Be flexible and self-motivated.

- Be able to work in a team environment as well as working independently. 
- Be able to work in a cross cultural setting and adjust to living in a different country.

- Provide one academic referee and one personal referee.

Some features and assistance of the internship included:

- An internship with a leading construction company and University in Hong Kong.

- Some financial support (up to $\$ 2000$ was provided by DFAT for each participating student).

- Pre-departure information sessions including a cross-cultural seminar.

- 24/7 support from WSU Careers Unit.

- Assistance with airfare and transportation

- Assistance with accommodation.

- Assistance with Visa processing.

- Travel insurance.

Twenty student applications were received for the ten scholarship awards available and all applicants were interviewed. Interview questions for the selection process were designed to ascertain student's motivation towards the global mobility program and their understanding of the multicultural environment of the host country. Interview questions explored student's understanding of work experience and the hosting organisations. Through the interview process they were also assessed as to how well they communicate.

\subsection{The Placement}

The two Directors of Academic Programs (DAPs) for the CM discipline and WSU Career Unit arranged for the successful students to work at one of the following leading construction companies in Hong Kong during January 4 to February 5, 2016:

\begin{tabular}{llc}
\hline Host Company & Area of Expertise & Student no. \\
\hline Company A & $\begin{array}{l}\text { Quantity Surveying } \\
\text { Civil engineering, building, foundations construction, electrical } \\
\text { \& mechanical installation, and fitting out works }\end{array}$ & 2 \\
Company B & $\begin{array}{l}\text { Construction, maintenance, renovation, design and build of } \\
\text { building projects } \\
\text { Construction, maintenance, renovation, design and build of } \\
\text { building projects }\end{array}$ & 2 \\
Company D & $\begin{array}{l}\text { BIM Research Lab, Industrial services covering Building } \\
\text { Information Modelling (BIM), process simulation solutions, and } \\
\text { professional training to the construction }\end{array}$ & 2 \\
\hline
\end{tabular}

Table 1: List of Host Company in Hong Kong for the industrial placement

\section{Results and Discussion}

Outbound students worked on range of projects and functions including civil construction, contract administration, and Building Information Modelling (BIM). Each of the students had to sign an employment contract with their placement company. The employment contract outlined working hours, remuneration, code of conduct, responsibilities and their supervisor's details. A staff member from WSU also accompanied these students for one week to mentor them on the importance of this internship program and to monitor their progress. The staff member also had an opportunity to visit a number of construction sites and university facilities so as to collect information on modern construction facilities available within the university sector and construction industry in Hong Kong. 


\subsection{Student Experience: Construction Virtual Prototype Laboratory}

Facilities at a Construction Virtual Prototype Laboratory (CVPL) (Company E) provided students with training on BIM software applied to a real-life project. Technical and tutorial assistance was provided to students by technical officers. Students were also provided with daily tutorial activities with technicians and academics who monitored their progress. This training included an opportunity to visit the respective live construction sites and compare their computer models against progress on construction projects. Students provided feedback on the training on BIM and noted in their reflective journals that WSU had no such facilities at the moment and they acquired invaluable training on emerging topics such as BIM. These skills can assist them finding a job in the local and international market. The CM discipline at WSU is already considering implementation of BIM education in the current CM courses which lacks high level object oriented modelling for construction technology courses.

\subsection{Student Experience: Pre-cast Construction Fabrication Site}

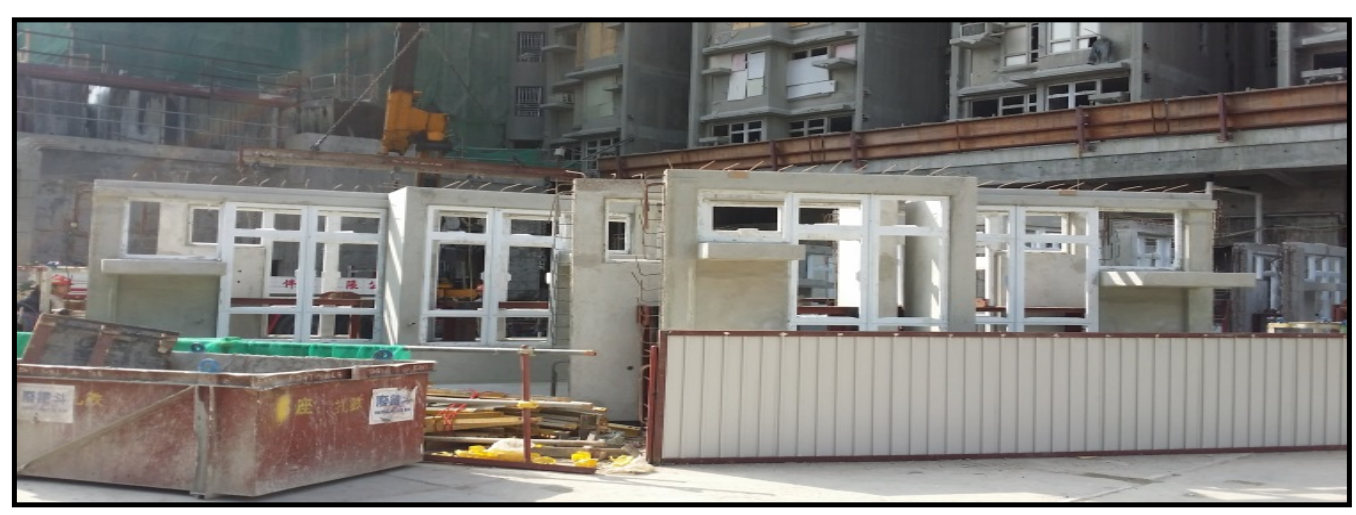

Figure 2: Company D site in Hong Kong for Precast construction

Students also worked on another BIM project (Company D) consisting of 7200 units across 9 blocks. All walls and ceilings were erected using pre-cast blocks with a batching plant on site. Figure 2 shows the photo of the precast construction components produced by Company D in Hong Kong. Students were excited about the use of modern construction methods and project management tools and provided positive feedback towards this internship program.

\subsection{Student Report and Interview}

As part of the condition of the scholarship all students submitted a reflective report at the conclusion of the placement. Students noted in their reflective reports and during the unstructured interview, how great the industry experience was. Some of the findings listed from the reflective diaries and interview included:

- Experience gained in an office environment and skills learned through work experience under the supervision of skilled professionals.

- Achievement of a variety of skills both personal and professional in nature, as well as enhanced confidence towards their professional career. 
- A sense of belonging for the first time in the industry and that the experience provided them with direction within their specific career path.

- New knowledge not taught as part of standard curriculum during their construction management degree at WSU.

- Knowledge gained in modern and alternative construction techniques and how the techniques linked to theory.

- Recognised future opportunities in their employability in both local and overseas markets.

- Experience gained in BIM modelling software.

- Strengthened interpersonal and communication skills in the workplace.

\subsection{Employer Survey Report}

Industrial partners were also surveyed online and they were pleased with student work efforts and the feedback received. All students completed their internship satisfactorily with four out of the five survey responses indicating they would recommend the program to other organisations. Three out of five industry partners said they would participate in the program again, two were undecided.

There were some negative comments from one Industry Partners as two students failed to inform their supervisor about their absence from work on one occasion.

\subsection{Student Responses}

The program proved to be popular among CM students though students had a hard time adjusting in the first week of their internship. Despite the hardships related to a new culture and language barriers, students showed resilience, adaptability and a positive mind-set which allowed them to further problem solve and gain the most out of their experience. Students enjoyed the Hong Kong program and gained outstanding practical skills in project management and hands on experience with building construction projects in Hong Kong's construction management sector. It is worth mentioning that the proportion of Australian students with an international study experience increased from $8.8 \%$ of domestic bachelor degree graduates in 2008 to $16.5 \%$ in 2014 (AUIDF, 2014). This is comparable with the United States undergraduate participation rate of 14.8\% in 2013-2014 (AUIDF, 2014).

\section{Conclusion}

Interviews with students and information from their reflective reports indicated that the outbound students experienced new understandings of their own discipline. They had greater understanding of the difficulties in construction and construction processes beyond that available locally. Outbound students also felt they had improved their employability and global knowledge through participation in this program. The greatest gain identified was the initiation to global networks and professional contacts within the construction discipline. Anecdotal feedback also indicated the project was a transformational experience for all participating students. New understandings, skills and knowledge not covered in current domestic curricula were highlighted by the students as one of the successes of the project. The opportunities arising from discipline and professional networks, was also considered to be invaluable. Future employability was noted by a number of the students as a vital outcome. The Construction Management Department of the Western Sydney University was also able to make valuable industry connections in Hong Kong. This case study created opportunities for professional development and improved industry skills and knowledge 
for students and staff. It is likely the new partnerships with the host companies will be continued and the possibility of BIM related exchanges across the CM discipline further developed.

\section{Acknowledgments}

The logistic and support provided by the Office of Learning and Teaching (OLT) funded project chief investigator Dr Patricia McLaughlin from RMIT is gratefully acknowledged. The authors are also grateful to Siobhan Markus, Projects Assistant, WSU Careers Unit, Freny Tayebjee, Manager Careers Unit and Dr Mary Hardie, Director of Academic Programs (Construction) for their contribution with the interviews, surveys and final report.

\section{References}

AIM Overseas. (2017). VET Sector Outbound Mobility Handbook and Toolkit, Department of Education \& Training, Australian Government. Retrieved from https://internationaleducation.gov.au/Endeavour\%20program/studentmobility/resources/Documents/V ETToolkit.pdf [accessed, 23 March 2017]

AUIDF. (2014). Students from Australian Universities in Learning Abroad 2014, Australian Universities International Directors Forum (AUIDF). Retrieved from http://www.cisaustralia.com.au/uploads/files/auidf-students-from-australian-universities-in-learningabroad-2014.pdf

Beard, D.F. (2007). Assessment of Internship Experiences and Accounting Core Competencies. In Accounting Education: an International Journal, Vol. 16(2), pp. 207-220, 2007.

Hardie, M. and Saha, S. (2016). 'The Impact of International Work Placements on Construction Undergraduates', Proceedings of the 40th Australasian Universities Building Education Association Conference, AUBEA 2016: Radical Innovation in the Built Environment, 6-8 July 2016, Cairns, Australia, 99-108. Retrieved from http://aubea.org/

Knouse, S.B., Tanner, J.R. and Harris, E.W. (1999). The Relation of College Internships, College Performance, and Subsequent Job Opportunity. In Journal of Employment Counselling, Vol. 36(1), pp. 35-43, 1999.

McLaughlin P., Baglin J., Chester A., Bedford A., Hadgraft R., Poronnik P., Hinton T., Mills A., Davis P., Saha S., \& Lawson J. (2017). The Global Canopy, Canberra, ACT. Retrieved from http://www.olt.gov.au/resources/good-practice?text=GLOBAL+CANOPY [accessed 4 April 2017].

Mendez, R. (2008). The Correlation between Industrial Placements and Final Degree Results: A Study of Engineering Placement Students. In ASET Conference, September 2-4, in Plymouth, 2008.

Narayanan, V.K and Olk, P.M. (2010). Determinants of Internship Effectiveness: An Exploratory Model. In Academy of Management Learning and Education, Vol. 9(1), pp. 61-80, 2010.

New Colombo Plan. (2016). New Colombo Plan Mobility Program Guidelines 2016 Round.

Retrieved from http://dfat.gov.au/people-to-people/new-colombo-plan/mobilityprogram/Pages/mobility-program-guidelines-2016.aspx, [accessed 2 June 2017]

Pirie, T. and McNicholoas, C. (2015). From Placement to Academic Meltdown: A Qualitative Study of Student Experience in the Transition From Third Year Work Placement Back to Fourth Year Academic Study. In Enhancement and Innovation in Higher Education, 9-1, June 2015, Glasgow, UK, 2015.

Price Waterhouse Coopers (2017). Global mobility. Retrived from http://www.pwc.com.au/people/global-mobility.html, [accessed, 23 March 2017].

Yin, R.K. (2014). Case Study Research Design and Methods (5th ed.).. Thousand Oaks, CA: Sage. 282 pages. 